\title{
PKM Revitalisasi Islam Wasatiyah: Moderasi Pemikiran Kader PMII Komisariat Universitas Nurul Jadid
}

\author{
Ainul Yakin ${ }^{1}$, Hafilul Fawaid ${ }^{2}$, Achmad Ainur Rafiq ${ }^{3}$, Faqih Thariqu Billah \\ Affan Muzakki ${ }^{5}$, Supandi ${ }^{6}$, Maulidi Iksan ${ }^{7}$, Mahbubatul Hafifi, \\ Muhammad Sofwan Hadi ${ }^{9}$ \\ Universitas Nurul Jadid, Probolinggo 1, 2, 3, 4, 5, 6, 7, 8, 9 \\ \{ainulyakin@unuja.ac.id\}
}

Submission: 2021-03-02 Received: 2021-04-23 Published: 2021-04-30

\begin{abstract}
Keywords:
Revitalization, Islam wasatiyah, Islamic

Moderation, PMII Nurul Jadid

Abstract. In the midst of the rise of Islamic movements with various ideologies, understandings and backgrounds in our country lately, it is quite worrying about the image of Islam and the integrity of the nation. This movement has not only touched the basis of culture and organization which has been considered extreme, radical and intolerant, but has begun to enter into the basis of culture and organization whose ideological affiliations are known to be tolerant and moderate. Therefore, this PKM tries to provide assistance to certain cadre organizations, namely, the Indonesian Islamic Student Association (PMII), the Nurul Jadid University Commissariat (UNUJA) which is based in pesantren as an effort to internalize the understanding of Islam wasatiyah. The method and approach used is a participatory approach. The result of this service is that the Islamic wasatiyah Paradigm presents the value of tolerance, public relations-dialog, prioritizes the strength of brotherhood, justice, upholds tolerance between religions, tribes and groups in order to avoid extreme behavior that threatens the integrity of the nation.
\end{abstract}

Kata kunci:

Revitalisasi,

Islam wasatiyah, Moderasi Islam, PMII Nurul Jadid

\begin{abstract}
Abstrak. Di tengah maraknya gerakan Islam dengan beragam ideologi, paham dan latar belakang di negara kita belakangan ini, cukup menghawatirkan citra Islam dan keutuhan bangsa. Gerakan tersebut tidak hanya menyentuh basis kultur dan organisasi yang selama ini dianggap ekstreim, radikal dan intoleran, tapi sudah mulai masuk pada basis kultur dan organisasai yang afiliasi ideoginya dikenal toleran dan moderat. Oleh karenanya, PKM ini mencoba melakukan pendampingan pada organisasi pengkaderan tertentu yaitu, Persatuan Mahasiswa Islam Indonesia (PMII) Komisariat Universitas Nurul Jadid (UNUJA) yang berbasis di pesantren sebagai upaya internaliaisasi pemahaman Islam wasatiyah. Metode dan pendekatan yang digunakan adalah pendekatan partisipatoris. Hasil dari pengabdian ini bahwa Paradigma Islam wasatiyah menyajikan nilai toleransi, humasnis-
\end{abstract}


dialogis, mengutamakan kekuatan persaudaraan, keadilan, menjunjung toleransi antar umat beragama, suku dan golongan guna menghindari perilaku ekstrem yang mengancam keutuhan bangsa.

\section{Pendahuluan}

Sebagai organisasi kader, konstribusi gerakan PMII Komisariat Universitas Nurul Jadid (UNUJA) sejauh ini cukup dirasakan masyarakat kampus khususnya kalangan mahasiswa. Sejumlah program dan terobosan mereka seperti kajian sosial dan keislamana, kegiatan jurnalistrik, advokasi dan kaderisasi memiliki posisi penting untuk mengubah cara pandang dan semangat pergerakan di lingkungan mahasiswa. Diterimanya keberadaan PMII sebagai organiasi ekstra kampus di lingkungan UNUJA tidak lepas dari basis ideologi dan kultur UNUJA sebagai perguruan tinggi pesantren yang afilisasi organisasinya adalah Nahdlatul Ulama (NU). Sementara PMII lebih dekat, bahkan sebagai organisasi kader pergerakan nahdliyyin.

Ditengah maraknya gelombang gerakan Islam belakang ini seperti eks Front Pembela Islam (FPI), eks Hizbut Tahrir Indonesia (HTI) dan lain sebagainya, yang cenderung "keras" dan "intoleran", PMII sebagai organisasi kader gerakan yang berbasis Islam dirasa perlu untuk melakukan counter wacana sebagai pengimbang derasnya gerakan tersebut. Islam wasatiyah menjadi penting kemudian untuk diusung sebagai wacana dan gerakan Islam yang lebih ramah dan humanis.

Sementara pada sisi lain, pemikiran keislaman kader PMII Komisariat UNUJA masih cukup beragam, ada yang cenderung konserfatif, modern, bahkan liberal, sekalipun secara umum dapat dikategorikan sebagai Islam yang mederat. Oleh karenanya PKM ini mencoba melakukan pendampingan kepada kader PMII Komisariat UNUJA sebagai bekal dan pengayaan wawasaan keislaman yang moderat sebagai pemikiran alternatif. Dini menjadi penting kemudian untuk melakukan pendampingan guna melahirkan wawasan yang lebih sesuai dengan kultur Islam nusantara sebagaimana yang telah dipraktikkan para pendahulu kita.

Berangkat dari latar belakang persoalan di atas, maka tujuan yang hendak dicapai dalam pengabbdian ini adalah:

a. Internalisasi pemikiran Islam wasatiyah sebagai wawasan keislaman alternatif di kalangan mahasiswa sebagai kader mahasiswa Islam. 
b. Lahirnya kesadaran keberagamaan yang lebih toleran, humanis dan moderat di lingkungan kampus, sehingga dapat ditularkan pada kader mahasiswa Islam yang di luar organisasi PMII.

c. Menghidupkan kembali kultur dan praktrik Islam nusantara di lingkungan kampus utamanya kampus Islam

\section{Metode}

Metode yang digunakan PKM pada pengabdian ini adalah metode partisipatoris. Partisipasi sebenarnya berasal dari bahasa inggris yaitu dari kata "participation" yang dapat diartikan suatu kegiatan untuk membangkitkan perasaan dan diikutsertakan atau ambil bagian dalam kegiatan suatu organisasi. Sehubungan dengan partisipasi masyarakat dalam menghidupkan tradisi, partisipasi merupakan keterlibatan aktif masyarakat. Jadi partisipasi disini dapat berarti keterlibatan proses penentuan arah dari strategi dalam membangun masyarakat dapam rangka menghidupkan tradisi amaliah Islam Nusantara yang dilaksanakan PKM.

Dalam pelaksanaan PKM tentu dibutuhkan rangsangan dari masyarakat dalam keikutsertaannya memiliki motivasi. Menurut Simatupang (dalam Yuwono, 2001:124) memberikan beberapa rincian tentang partisipasi sebagai berikut:

a. Partisipasi berarti apa yang kita jalankan adalah bagian dari usaha bersama yang dijalankan bahu-membahu dengan saudara kita sebangsa dan setanah air untuk membangun masa depan bersama

b. Partisipasi berarti pula sebagai kerja untuk mencapai tujuan bersama diantara semua warga negara yang mempunyai latar belakang kepercayaan yang beraneka ragam dalam negara pancasila kita, atau dasar hak dan kewajiban yang sama untuk memberikan sumbangan demi terbinanya masa depan yang baru dari bangsa kita.

c. Partisipasi tidak hanya berarti mengambil bagian dalam pelaksanaanpelaksanaan, perencanaan pembangunan. Partisipasi berarti memberikan sumbangan agar dalam pengertian kita mengenai pembangunan kita nilai-nilai kemanusiaan dan cita-cita mengenai keadilan sosial tetap dijunjung tinggi.

d. Partisipasi dalam pembangunan berarti mendorong ke arah pembangunan yang serasi dengan martabat manusia. Keadilan sosial dan keadilan Nasional dan yang memelihara alam sebagai lingkungan hidup manusia juga untuk generasi yang akan datang. 
Sementara dalam konteks pembangunan, menurut Suryono (2001:124) partisipasi merupakan ikut sertanya masyarakat dalam pembangunan, ikut dalam kegiatan pembangunan dan ikut memanfaatkan dan menikmati hasilhasil pembangunan.

Selain motode di atas, agar hasil PKM lebih tepat sasaran dan berdaya guna, pendekatan yang diambil adalah diskusi dan tanya jawab dengan metode Focus Group Discussion (FGD). Metode tersebut digunakan guna pengumpulan data dalam PKM. Pengambilan data kualitatif melalui FGD ini memberikan kemudahan dan peluang bagi pelaksana untuk menjalin keterbukaan, kepercayaan, dan memahami persepsi, sikap, serta pengalaman yang dimiliki informan. FGD memungkinkan PKM dan informan berdiskusi intensif dan tidak kaku dalam membahas isu-isu keislaman saat ini. Metode ini juga memungkinkan PKM mengumpulkan informasi secara cepat dan konstruktif dari peserta yang memiliki latar belakang berbeda-beda.

Di samping itu, dinamika kelompok yang terjadi selama berlangsungnya proses diskusi seringkali memberikan informasi yang penting, menarik, bahkan kadang tidak terduga. Sebaba hasil FGD tidak bisa dipakai untuk melakukan generalisasi karena tidak bertujuan menggambarkan (representasi) suara mahasiswa. Meski demikian, metode tersebut bukan terletak pada hasil representasi kader PMII, tetapi pada kedalaman informasinya. Lewat FGD, PKM bisa mengetahui alasan, motivasi, argumentasi atau dasar dari pendapat peserta secara mendalam dan objelktif sehingga PKM betul-betul tepat sasaran dan sesuai kebutuhan lapangan.
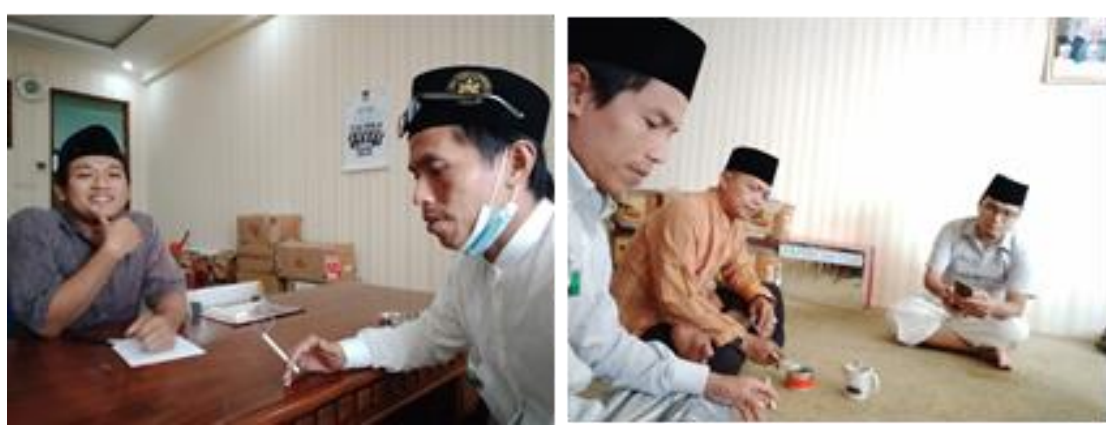

Gambar 1. Observasi dan wawancara pendahuluan sebelum dilakukan PKM

3 Hasil

a. Dinamika Wacana Islam: Mengenalkan Gerakan Islam Kontemporer 
Selama dilakukan pendampingan terhadap pengurus Komisariat PMII Unuja, peserta relativ aktif. Hal ini tidak lepas dari pendekatan yang dilakukan dalam PKM. Sekalipun menggelar PKM dalam pemikiran Islam hal yang tidak mudah. Soalnya berkaitan dengan cara pandang, wawasan dan latar belakang keilmuan masing-masing peserta. PKM yang digelar di pesantren Nurul Jadid ini dihadiri oleh ketua komisariat, Abdur Razak dan sebagian anggota Rayon. Ketua Komisariat PMII ujuna mengatakan, bahwa pendampingan ini sangat penting untuk mencetak kader-kader ideologis yang militan. Apa lagi kegiatan ini mengambil tema keislaman yang saat ini sangat relevan yaitu Islam wasatiyah. ${ }^{2}$ yang sanagmengambil tema 'mempertajam basis ideologi kader melalui nalar kritis khazanah keilmuan.

Sebab dengan banyaknya ideologi yang masuk di negeri ini perlu memantabkan ideologi para kader. PMII sebagai kader mudanya NU, selain meneguhkan idiologi kader juga untuk mematangkan keilmuan keilmuan tentang keislaman khsusnya pemikiran keislaman. "Kita harus bersama-sama berjuang untuk terwujudnya kader idiologis," jelasnya. Sementara, Hafulul Fawaid, Selaku Anggota PMII, menambahkan bahwa kajian dengan model pendampingan orang yang kompeten seperti ini sangat dibutuhkan, khususnya untuk kader-kader PMII. Karena melihat keadaan sekarang yang semakin banyak ideologi yang masuk. "Saya sangat mengapresiasi betul program inovasi kampus dalam PKM pemikiran islam ini. dia berhapar agar ke depan kita PMII mampu menjadi organisasi yg secara kuantitas maupun kualitas dapat diandalkan. ${ }^{3}$ Hal ini senada dengan apa yang disampaikan wakil sekretaris PC NU Tuban, Jamal Ghofir yang menyarankan agar menjadi aktifis yang baik. Aktivis tentu harus harus berproses yang sungguh-sungguh dalam organisasi dan keilmuan. Karena menjadi aktivis yang baik tidak mudah, harus punya tanggungjawab sebagai mahasiswa baik dalam bidang keilmuan maupun bidang sosial kemasyarakatan.

Untuk memudahkan penyerapan PKM, pendamping mencoba mengguankan metode FGD dengan melibatkan partisipasi peserta secara aktif. Di tengah-tengan diskusi, pendamping menoba mengutip pendapat Prof. Quraish Shihab tentang Islam wasatiyah. Beliau mengemukakan bahwa

\footnotetext{
${ }^{2}$ Abd Razak, Ketua Komisariat PMII Unuja periode 2021-2023, Wawancara, Probolinggo, 21 Januari 2021.

${ }^{3}$ Hafilul Fawaid, pengurus Komisariat PMII Unuja periode 2021-2023, Wawancara Pendahuluan, Probolinggo, 21 Januari 2021.
} 
terdapat tiga kunci seseorang bisa menerapkan wasatiyah atau moderasi beragama. Tiga kunci tersebut adalah pengetahuan, mengganti emosi keagamaan dengan cinta agama, dan selalu berhati-hati. Senada dengan pendapat Prof. Quraish Shibab, yaitu pandangan Kiai Ma'ruf Amin, saat ini sebagai wakil Presiden RI juga menjadi rujukan dalam diskusi forum. Kiai Ma'rif mengemukakan bahwa wasatiyah adalah model ekspresi dan pemahaman yang relevan dalam bingkai kenegaraan di Indonesia. ${ }^{4}$

Tentang Islam wasatiyah, Kiai Ma'ruf Amin juga mengemukakan bahwa ada empat kaidah dalam ajaran Islam Wasthiyah. Yang pertama yaitu santun, tidak keras dan tidak radikal. Kedua memiliki rasa rela, tidak memaksa dan tidak mengintimidasi. Ketiga adanya toleransi, tidak egois dan tidak fanatis. Terakhir, saling mencintai, tidak saling bermusuhan dan membenci. ${ }^{5}$ Berangkat dari pemberian materi di atas, peserta cukup menyerap sesuai target yang diaharpakan.

Guna menpertajam pemahaman terhapad tema PKM, pendamping menyusun materi secara sistematis yang sesuai dengan tema. Pada materi tersebut, peserta tidak hanya dibekali tentang wawasan Islam wasatiyah, tapi juga materi lain seperti peta gerakan Islam, akar dan sejarah gerakan ekstremisme, nilai-nilai Islam wasatiyah dan cara memnumikannya. Agar lebih mudah dipahami, berikut kami tampilkan materi PKM.

Tabel 1. Materi PKM Kader dan Aktifis PMII Komisariat

Universitas Nurul Jadid 2021

\begin{tabular}{llll}
\hline No & Tema & Pendamping & Waktu \\
\hline \multirow{2}{*}{1} & Gerakan Ekstremisme dan & Peserat PKM, & PKM dilakukan \\
& $\begin{array}{l}\text { Radikalisme Islam: Sejarah, Akar } \\
\text { dan Sempalannya }\end{array}$ & $\begin{array}{l}\text { dipandu dosen } \\
\text { Pendamping }\end{array}$ & $\begin{array}{l}\text { selama satu bulan, } \\
\text { sejak tanggal 20 }\end{array}$ \\
\hline
\end{tabular}

${ }^{4}$ Hal tersebut disampaikan KH. Maruf Amin saat memberikan kuliah umum pada 17 Oktober 2018 di S. Rajatnam School of International Studies, Nanyang Technological University (RSiS NTU) Singapura. Kala itu ia berbicara tentang Rekonsolidasi Islam Moderat dan Ekonomi Berkeadilan di Indonesia.

5 dan panduan setiap gerakan MUI di semua tingkatan dalam merumuskan kebijakan. Tentang Islam Wasathiyah juga banyak dibahas dalam Alquran. Di antaranya dalam surat Al-Baqarah ayat 143 yang berbunyi:

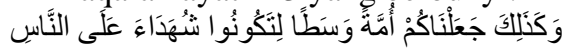

"Demikian juga aku ciptakan kamu sekalian sebagat umat yang wasath agar supaya menjadi saksi kepada ummat manusia dan supaya rasul menjadi saksi kepada kamu sekalian." Pada ayat tersebut dijelaskan jika kualifikasi umat yang baik adalah ummatan wasathan. Ciri dari Islam Wasathiyah yaitu pertengahan atau moderasi, menghindari segala bentuk kekerasan dan sekaligus merujuk memiliki sikap adil. Dengan memahami ciri dan pengertian seperti yang dijabarkan di atas, maka umat Islam mampu menjalankan agamanya secara wasathiyah. 


\begin{tabular}{llll}
\hline No & Tema & Pendamping & Waktu \\
\hline \multirow{2}{*}{$\begin{array}{ll}\text { Peta Gerakan Islam: Konstalasi } \\
\text { Gerakan Islam Kontemporer di } \\
\text { dunia Islam }\end{array}$} & Januari - 20 \\
\cline { 1 - 2 } 3 & $\begin{array}{l}\text { Nilai-Nilai Islam wasatiyah: } \\
\text { Menuju Masyarakat } \\
\text { Berperadaban }\end{array}$ & \\
\hline \multirow{2}{*}{$\begin{array}{l}\text { Revitalisasi Islam Wasathiyah: } \\
\text { Upaya Moderasi Islam di } \\
\text { Nusantara }\end{array}$} & \\
\hline
\end{tabular}

Berangkat dari materi di atas, diskusi menjadi lebih hidup, peserta dan pendamping masuk pada forum diskusi yang tajam. Tidak kalah menariknya saat pemberian materi gerakan Islam kontemporer, sehingga peserta menjadi lebih paham terhadap peta gerakan Islam, akar sejarah dan gerakan ektremisme sebagaimana pengakuan Achmad Ainur Rafiq. ${ }^{6}$ Materi yang disiapkan pendamping ternyata sangat membantu peserta dalam memahami gerakan Islam, sehingga mereka dapat mengambil sikap mengapa harus memilih Islam wasatiyah sebagai paradigma gerakan.

\section{b. Revitaliasi Islam Wasthiyah: Dari Wacana Menuju Tindakan}

Sebagaimana yang telah disebutkan sebelumnya, agar pedampingan berjalan efektif, terarah, mencapai target dan berdaya guna, metode penyampaian materi dilakukan dengan diskusi melalui metode Focus Group Discussion (FGD). Mula-mula pendamping membentuk kelompok menjadi dua kelompok diskusi. Hal tersebut dimaksudkan untuk mengahasilkan informasi guna mengukur kemampuan peserta dalam memahami isu Islam wasatiyah sebagai tema besar. Sehingga diskusi yang dilakukan berjalan secara sistematis dan terarah mengenai suatu isu tersebut. Proses pengumpulan data atau informasi kemudian ditindaklanjuti melalui diskusi kelompok yang telah dikalsifiaksi, sehingga disikusi berjalan tlebih terarah dan sistematis pada saat membahas isu yang sangat spesifik tentang Islam wasatiyah.

Setelah langkah di atas dilakukan, sebelum masuk tema pokok, pendamping memberikan tema pengantar yaitu Gerakan Ekstremisme dan

6 Peserta PKM dari unsur mahasiswa non PMII, tapi ia terlibat aktif baik sebagai pendamaping maupun sebagai peserta. Probolinggo, 18 Februari 2021. 
Radikalisme Islam: Sejarah, Akar dan Sempalannya. Tema tersebut sebagai pintu masuk untuk memahami lebih jauh tentang Islam wasatiyah. Dalam diskusi tema tersebut peserta sangat aktif, diskusi berjalan dengan lancar, sekalipun di sana disini masih ada yang perlu diluruskan. Pendamping hanya memberikan materi pengantar yang telah disediakan dalam bentuk PPT. Pada diskusi awal ini peserta dikenalkan adanya gerakan ektremisme dan radikalisme di dunia Islam. Hal tersebut dilakukan sebagai upaya membuka cakrawala pemikiran peserta agar memahami Islam wasatiyah nantinya lebih utuh. Dibawah ini adalah salah satu dokomen saat diskusi tema.
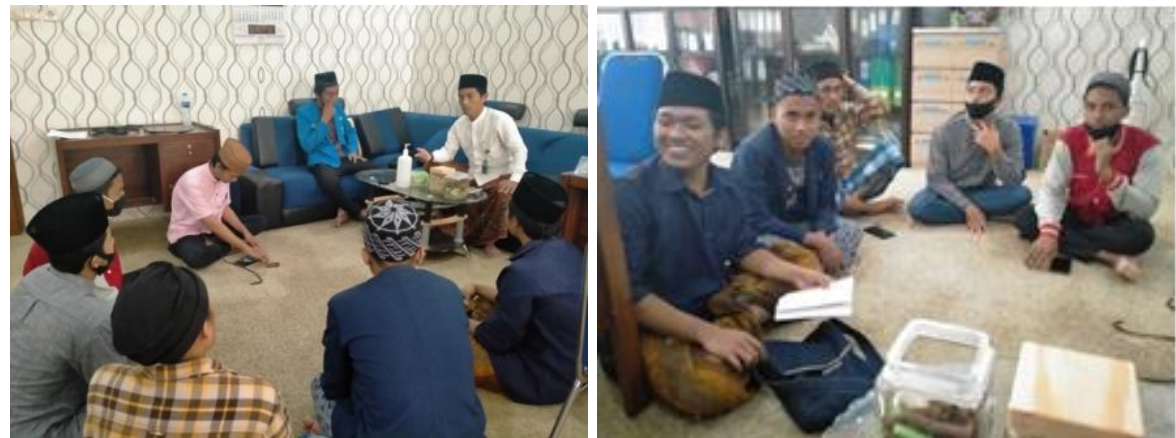

Gambar 2. Pendamping PKM memandu jalannya diskusi dengan model FGD

Salanjutkan adalah tema tentang Peta Gerakan Islam: Konstalasi Gerakan Islam Kontemporer di Dunia Islam. tema ini sengaja diambil guna memberi pemahaman kepada peserta tentang peta gerakan Islam modern berbagai belahan dunia Islam. Metode penyampaian materi dilakukan secara partipatoris dan diskusi model FGD. Untuk mempertajam pemahaman materi, peserta melakukan mapping terhadap gerakan yang terjadi di dunia Islam, baik gerakan keagamaan, politik-ekonomi dan sosial budaya. Peserta tetap ambil porsi yang optimal agar semua dapat menyerap dengan utuh. Untuk memparkaya wawasan, pendamping menyediakan materi yang bersumber dari buku bacaan, majalah, dan internet.

Setelah dua materi diatas tersampaikan, pada sesi selanjutnya adalah sesi ketiga. Pada sesi tersebut masuk pada pokok pembahasan, yaitu Islam wasatiyah. Tema yang diambil adalah Nilai-Nilai Islam wasatiyah: Menuju Masyarakat Berperadaban. Sebelum masuk pada nilai-nilai yang menjadi dasar Islam wasatiyah peserta dikenalkan makna Islam wasatiyah secara etimologis dan termenologis. Secara terminologi wasatiyah yang didiskusikan dalam PKM berakar dari bahasa Arab "wasath", memiliki arti 
leksikal "pertengahan". Dalam penggunaan sehari-hari, wasath merujuk pada sikap yang berada di tengah-tengah antara berlebihan (guluw) dan kurang (qasr). Parameter berlebihan dan kurang dalam konteks sikap tersebut adalah batas-batas aturan yang ditetapkan agama. ${ }^{7}$

Adapun rumusan definisi wasatiyah sebagai berikut:

$$
\begin{aligned}
& \text { الاعتدال في كل أمور الحياة من تصورات ومناهج ومواقف، وهي تحر متواصل } \\
& \text { مجرد موقف بين التشدد والانحلال؛ بل للصواب في التوجهات والاختيارات، فالوسطية ليست } \\
& \text { هي منهج فكري وموقف أخلاقي وسلوكي } 8
\end{aligned}
$$

Dari definisi di atas wasatiyah tidak sekedar sikap mengambil posisi tengah di antara dua sisi radikal dan liberal. la merupakan metode berfikir yang berimplikasi secara etik untuk diterapkan sebagai kerangka perbuatan tertentu. Istilah wasat (akar kata wasatiyah) diterjemahkan ke dalam bahasa Indonesia sebagai 'moderat'. Kamus Besar Bahasa Indonesia (KBBI) merumuskan definisi 'moderat' pada dua level, yaitu; (1) selalu menghindarkan perilaku atau pengungkapan yang ekstrem; (2) berkecenderungan ke arah dimensi atau jalan tengah, mau mempertimbangkan pandangan pihak lain. ${ }^{9}$ Definisi ini meletakkan pengertian moderat berlawanan secara diametral dengan sikap ekstrim di satu kutub dan liberal pada kutub lain.

Sementara dalam diskursus teoretis tentang wasatiyah dalam Islam modern masih beragam, kalangan intelektual muslim merumuskan konsepsi moderatisme Islam dalam perspektif yang berbeda-beda. Oleh Khaled Abou El Fadl, pemakaian istilah moderat secara tegas dikontraskan dengan 'puritan'. Seorang muslim yang moderat, kata Khaled adalah orang-orang yang yakin pada Islam sebagai keyakinan yang benar, yang mengamalkan dan mengimani lima rukun Islam, menerima warisan tradisi Islam, namun sekaligus memodifikasi aspek-aspek tertentu darinya.

Mereka tidak memposisikan Islam seperti monumen yang beku dan sebaliknya menempatkannya dalam sudut pandang iman yang dinamis dan aktif. Konsekuensinya, mereka menghargai pencapaian-pencapaian masa silam tetapi mereka (sadar) hidup di zaman sekarang. Kata kunci untuk

\footnotetext{
${ }^{7}$ Syaikh Muhammad bin Shalih al-Usaimin, "Ma'na al-Wasith fi ad-Din”, terj. Muhammad Iqbal Ahmad Ghazali, dalam islamlib.com, 2010. Diakses pada sabtu, 28 Oktober 2017, pukul 08.33 WIB.

${ }^{8}$ https://ar.wikipedia.org/wiki/( إسلام_وسطية), diakses pada tanggal 24 Febrruari 2021.

${ }^{9}$ https://kbbi.web.id/moderat, diakses tanggal 20 Februari 2021, pukul 11.00 WIB.
} 
memahami konsepsi moderatisme Islam Khaled terletak pada kesadaran seorang muslim terhadap keyakinan doktrin dan realitas dimana dan kapan dia hidup. Sikap seperti ini berarti membawa cara pandang dialektis terhadap aspek legal spesifik-ideal moral (Rahman), historisitas-normatifitas (Rahman, Amin Abdullah), normatif-empiris (Mukti Ali), al-Kita>b-at-tanzi>l (Syahrur) dan sisi-sisi berlawanan lain dalam wajah Islam. ${ }^{10}$

Sedangkan Ummi Sumbulah menarik definisi moderat dalam terma "Islam agama damai". Agama damai di sini mengandung dua pengertian, yaitu; pertama, pengertian pasif dimana setiap orang Islam memiliki visi untuk menginternalisasikan "kemaslahatan" bagi dirinya dalam rangka menghayati dimensi kemanusiaan yang melekat pada diri mereka. Kedua, dalam pengertian aktif, Islam damai menjadi misi setiap umat Islam untuk mendakwahkan dan menciptakan suasana kondusif dalam struktur masyarakat yang plural. Pengertian kedua ini mewariskan pemahaman kolektif bahwa kemaslahatan tidak dibatasi oleh kategori personal, melainkan bersifat sosial. ${ }^{11}$

Jika Khaled merumuskan Islam moderat dari perspektif cara pandang muslim terhadap agama dan realitas, maka Ummi Sumbulah lebih konkret lagi melihat dari perspektif keyakinan seorang muslim dan aktualisasinya dalam konteks kehidupan yang lebih luas. Lebih rinci Qardhawi merumuskan kriteria Islam wasatiyah yang terdiri atas dua puluh indikator dimana kesemuanya berisi prinsp-prinsip yang harus diterapkan oleh umat Islam. Ada dua puluh prisip Islam wasat\}iyah tersebut adalah: (1) menjaga keseimbangan antara ketetapan syara' dan dinamika realitas kontemporer, (2) memahami nus\}us\} yang spesifik dalam al-Qur'an dan as-sunnah dalam rangka merealisasikan tujuan-tujuan umum, (3) membuat mudah fatwa dan dakwah yang menyenangkan, (4) berpegang teguh pada ushul dan kulliyat dan sebaliknya fleksibel dalam menerapkan furu' dan juz'iyat, (5) fokus pada tujuan dan toleran dalam menentukan sarana untuk mencapainya, (6) lebih menekankan substansi daripada bentuk, yang batin daripada yang zahir, amal hati daripada fisik, (7) memiliki pemahaman komprehensif tentang islam, baik

\footnotetext{
${ }^{10}$ Ahmad Dimyati, Islam Wasatiyah: Identitas Islam Moderat Asia Tenggara dan Tantangan Ideologi, Islamic Review: Jurnal Riset dan Kajian Keislaman, Vol. VI No.2 Tahun 2017, 141.

${ }^{11}$ Ummi Sumbulah, "Islam dan Risalah Profetik: Best practice Moderasi dan Kerahmatan", M. Zainuddin dan Muhammad In'am Esha (editor), Islam Moderat; Konsepsi, Interpretasi dan Aksi (Malang: UIN Maliki Press, 2016), hlm. 168-169.
} 
dalam aspek akidah, syari'ah, dunia dan agama, dakwah dan daulah, (8) menjalankan dakwah bil hikmah, dan bersedia dialog dengan pihak lain dengan mengedepankan etika, (9) rekonsiliatif terhadap para pemimpin yang beriman serta toleran dengan pihak yang berbeda pandangan.

Adapun yang ke sepuluh (10), rela berjihad terhadap orang - orang yang melampuai batasan agama dan menyelamatkan sesama orang islam, (11) tolong-menolong dengan sesama faksi dalam islam yang sepaham dan toleran dengan yang berbeda pendapat, (12) mencermati perubahan yang diakibatkan perubahan waktu, tempat dan struktur sosial dalam menetapkan fatwa, berdakwah, mendidik maupun memutuskan hukum, (13) menerapkan metode bertahap dalam berdakwah, mengajar, berfatwa dan melakukan perubahan, (14) mengintegrasikan ilmu dan iman, inovasi materiil dan kenyamanan jiwa, otoritas dan ekonomi, serta mengutamakan kekuatan persaudaraan Islam, (15) menggalang dasar-dasar bagi tegaknya nilai humanisme dan sosial, seperti keadilan, musyawarah, kebebasan dan hakhak manusia, (16) membebaskan perempuan dari belenggu keterbelakangan dan pengaruh dari gempuran peradaban Barat, (17) menyeru pembaruan endogen agama dan menghidupkan urgensi ijtihad bagi mereka yang berkompeten dalam hal tersebut secara kontekstual, (18) memiliki motivasi kuat untuk membangun bukan merusak, rekonsiliatif bukan memecah belah, mendekatkan bukan menjauhkan, (19) mengambil pelajaran dari turas dari kecerdasan mutakallimun, kedalaman jiwa ahli tasawuf, kesetiaan tabi'in, serta keteguhan prinsip fuqaha' dan ushuliyun, dan (20) menyatukan warisan masa lalu, realitas sekarang dan kemuliaan masa yang akan datang. ${ }^{12}$

Dari diskusi konseptual pada sesi ketiga ini, dapat disimpulkan bahwa perbedaan beberapa definisi di atas, Islam wasatiyah dioperasionalkan dalam tiga level makna; yakni; (1) Level Teologis, (2) Level Ideologis; (3) Level sosiopolitis. Pada level teologis, Islam wasatiyah dikaitkan dengan interpretasi terhadap ayat-ayat dalam Alqur'an dan Hadis. Di sini doktrin Islam wasatiyah dianggap sebagai ajaran agama yang harus dipahami dan diterapkan. Berikutnya pada level ideologis, Islam wasatiyah merujuk pada perdebatan mengenai posisi umat Islam dalam dialog antar umat beragama. Perdebatan

\footnotetext{
${ }^{12}$ Yusuf al-Qardhawi, "Dawabit\} al-Manhaj al-Wusta", dalam www.wikipedia.org/,dikses 13 Februari 2021. Lihat juga Ahmad Dimyati, Islam Wasatiyah: Identitas Islam Moderat Asia Tenggara dan Tantangan Ideologi, Islamic Review: Jurnal Riset dan Kajian Keislaman, Vol. VI No.2 Tahun 2017, 144.
} 
ini ditujukan untuk mengukuhkan posisi umat Islam yang berada di tengah, moderat dan terbaik di antara umat-umat yang lain. Bahwa ummah wasat adalah konsep masyarakat ideal yang mampu menjaga harmoni yang berkesinambungan, dan peran tersebut dipegang oleh umat Islam. Masyarakat ideal yang dimaksud dapat diketahui melalui karakteristiknya, menyukai musyawarah, adil, mengutamakan persaudaraan dan menjunjung toleransi. ${ }^{13}$ Pada level sosio-politis, diskursus mengenai Islam wasatiyah ditarik pada konsep bernegara di bawah ideology tertentu.

Pada perjalanan diskusi PKM ini, peserta merasakan adanya perubahan cara pandang dengan pembekalan wacana keislaman kontemporer. Transformasi pemikiran kader PMII Komisariat UNUJA memberi konsekuensi logis bahwa secara otomatis mereka mengalami pencerahan dengan bertambahnya wawasan yang sebelumnya belum ditemukan untuk melakukan tindakan lebih nyata, tidak hanya sekadar pemahaman wacana dan teori tapi harus berujung tindakan praksis. Pada saat diskusi pendalaman di sesi ketiga dan keempat, pendamping tidak mengalami kendala yang cukup berarti dalam memberikan pemahaman tema. Hal itu tidak lepas dari materi sebelumnya, dan pengalaman kader serta ketua Komisarat sendiri yang pernah mengikuti pelatihan kederisasi di PMII, sebagaimana yang diakui sendiri oleh Abdur Razak. ${ }^{14}$

Jika dilihat lebih jauh, kecenderungan pemikiran mereka lebih dekat Islam waasatiyah karena nilai-nilai yang ditanamkan pada kader OMII salah satunya adalah menjaga hubungan baik dengan Allah, manusia dan alam. Oleh karenanya yang perlu dibangun adalah kesadaran sosial dengan menajaga toleransi, kesetaraan dan keadilan. ${ }^{15}$ Lingkunagn kampus yang ada di pesantren juga mendukung lahirnya pemikiran yang moderat. Sebab berbagai literatur bacaan-bacaan yang mereka berasal dari kitab klasik peninggalan ulama nusantara, yang berhaluan ahlus sunnah waljamaah

\footnotetext{
${ }^{13}$ Ali Nurdin, Qur'anic, 226-279. Istilah toleransi berasal dari kata tolerar (Latin) yang berarti menahan diri, sabar, menghargai orang lain, berbeda pendapat, berhati lapang dan memiliki tenggangrasa terhadap orang yang berlainan pandangan atau agama. Abdullah bin Nuh, Kamus Baru (Jakarta: Pustaka Islam, 1993), hlm. 199.

${ }^{14}$ Abdur Razak, Ketua PMII Komisariat Unuja. Dalam elaborasi dia saat menyampaikan tentang tema Islam wasatiyah dia mengungkapkan bahwa Islam yang dia gelorakan adalah paham Islam yang membangun hubungan dengan manusia dengan ramah, toleran, dan berimbang, serta menjaga kelestarian alam.

${ }^{15}$ Abdur Razak, Faqih Thariqu Billah, elaborasi pemahaman dan testemi pemikiran saat PKM, Probolinggo, 21 Februari 2021.
} 
(Aswaja). Sekalipun demikian, tidak semua peserta memahami secara utuh tentang pemikiran Islam yang moderat yang berkembang di kampus pesantren.

Oleh sebab itu, untuk memperkuat materi terakhit adalah Revitalisasi Islam Wasathiyah: Upaya Moderasi Islam di Nusantara. Materi ini disuguhkan pemahaman Islam wasatiyah tidak berhenti pada tataran wacana akan tetapi apliktif dalam kehidupan nyata. Proses pemahaman Islam wasatiyah di dalam warga PMII Komisariat Unuja ini berimplikasi pada tradisi pemahaman Islam yang ramah, santun, beradab dan humanis dalam menyeabrkan Islam. Pasca PKM kader PMII Ujuna sebagai organisasi yang berbasis Islam tradisional, justru mampu memunculkan wacana keilmuan yang melampaui batas tradisionalnya, bahkan bisa dikatakan melampaui batas kelompok moderisme Islam. PMII sangat jarang bahkan tergolong tidak pernah menjadikan rujukan-rujukan kelompok Islam modernis dalam diskursusdiskursus keilmuannya, seperti pemikiran Jamaluddin alAfghani, Sayyid Akhmad Khan, Natsir dan Nurcholis Majid. Akan tetapi PMII lebih memilih pemikiran tokoh-tokoh kiri seperti Hasan Hanafi, Muhammad Arkoun, al Jabiri dan Nasr Hamid Abu Yazid.

Walhasil, di tengah munculnya kelompok Islam yang intoleran, eksklusif, mudah mengkafirkan orang dan kaku, PKM ini setidaknya memberikan warna baru untuk menampilkan Islam yang lemah lembut dan rahmatn lil alamin. Selain itu kita juga dihadapkan pada munculnya komunitas Islam yang cenderung liberal dan permisif. Kedua kelompok tersebut tergolong kelompok ekstrem kanan (tatharruf yamini) dan ekstrem kiri (yasari), yang bertentangan dengan wujud ideal dalam mengimplementasikan ajaran Islam di Indonesia bahkan dunia. Bagi kita bangsa Indonesia khususnya, peserta PKM menolak pemikiran atau paham keagamaan dan ideologi serta gerakan kedua kelompok tersebut, karena tidak sesuai dan bahkan bertentangan dengan nilai-nilai dan prinsip-prinsip yang dianut dan dibangun bangsa Indonesia.

Karena itu merupakan hal yang sangat penting untuk mengembalikan umat Islam kepada ajaran ulama nusantara. Antara lain dengan mengembalikan pemahaman Islam wasatiyah. Allah SWT berfirman dalam QS. Al-Baqarah : 143 yang artinya : "Dan demikian (pula) Kami telah menjadikan kamu (ummat Islam); umat pertengahan (yang adil dan pilihan) agar kamu menjadi saksi atas (perbuatan) manusia dan agar Rasul 
(Muhammad) menjadi saksi atas (perbuatan) kamu". Praktik amaliyah keagamaan Islam wasatiyah meliputi: (1) Tawassuth (mengambil jalan tengah) yaitu pemahaman dan pengamalan yang tidak ifrath (berlebihlebihan dalam beragama) dan tafrith (mengurangi ajaran agama), (2) Tawazun (berkeseimbangan) yaitu pemahaman dan pengamalan agama secara seimbang yang meliputi semua aspek kehidupan baik duniawi maupun ukhrawi, tegas dalam menyatakan prinsip yang dapat membedakan antara inhiraf (penyimpangan) dan ikhtilaf (perbedaan), (3) I'tidal (lurus dan tegas), yaitu menempatkan sesuatu pada tempatnya dan melaksanakan hak dan memenuhi kewajiban secara proporsional, (4) Tasamuh (toleransi) yaitu mengakui dan menghormati perbedaan, baik dalam aspek keagamaan dan berbagai aspek kehidupan lainnya, (5) Musawah (egaliter) yaitu tidak bersikap diskriminatif pada yang lain disebabkan perbedaan keyakinan atau agama, tradisi dan asal usul seseorang, (6) Syura (musyawarah) yaitu setiap persoalan diselesaikan dengan jalan musyawarah untuk mencapai mufakat dengan prinsip menempatkan kemaslahatan di atas segalanya,

Selanjutnya, (7) Ishlah (reformasi) yaitu mengutamakan prinsip reformatif untuk mencapai keadaan lebih baik yang mengakomodasi perubahan dan kemajuan zaman dengan berpijak pada kemaslahatan umum (mashlahah 'amah) dengan tetap berpegang pada prinsip al-muhafazhah 'ala al-qadimi alshalih wa al-akhdzu bi al-jadidi al-ashlah (merawat tradisi merespon moderenisasi), (8) Aulawiyah (mendahulukan yang prioritas) yaitu kemampuan mengidentifikasi hal-ihwal yang lebih penting harus diutamakan untuk diimplementasikan dibandingkan dengan yang kepentingannya lebih rendah, (9) Tathawwur wa Ibtikar (dinamis dan inovatif) yaitu selalu terbuka untuk melakukan perubahan-perubahan sesuai dengan perkembangan zaman serta menciptakan hal baru untuk kemaslahamatan dan kemajuan umat manusia, (10) Tahadhdhur (berkeadaban) yaitu menjunjung tinggi akhlakul karimah, karakter, identitas, dan integritas sebagai khairu ummah dalam kehidupan kemanusiaan dan peradaban.

Praktik amaliyah keagamaan Islam wasatiyah ini perlu didakwahkan sebagai implementasi Islam Rahmatan Lil Alamin. Karena fenomena yang terjadi saat ini, tidak jarang dakwah dilaksanakan secara kurang terencana dan gencar dilaksanakan hanya berkaitan dengan perayaan hari-hari besar Islam atau bahkan di momen-momen politik. Hal ini pun masih menyisakan masalah seperti kompetensi da'i, kurangnya atensi (perhatian) mad'u pada 
materi-materi dakwah yang membuka wawasan umat, materi yang tidak mendalam dan tidak komprehensif, bahkan tidak jarang menonjolkan pencitraan diri atau kelompoknya, pemahaman radikal dan menyerang kelompok lain yang berbeda pemahaman, atau sebaliknya dengan pemahaman liberal yang cenderung permisif serba membolehkan dan menggampangkan. Untuk itu diperlukan sekelompok orang yang secara terus menerus mengkaji, meneliti dan meningkatkan aktivitas dakwah secara profesional. ${ }^{16}$

\section{Kesimpulan}

Dari hasil pengabdian yang dilakukan selama satu bulan ini menunjukkan bahwa:

a. Pasca dilakukan pendampingan, peserta PKM yang terdiri dari kader PMII Komisarit UJUNA berkomitmen lebih teguh dalam menyebarkan nilai-nilai Islam wasatiyah. Islam wasatiyah sejatinya merupakan ajaran ulama nusantara yang selama ini dianut dan diamalkan mayoritas umat Islam di Indonesia.

b. Spektrum pemikiran keislaman kader PMII Komisarita UNUJA secara umum tidak ada yang ekstrim, baik ekstrim kanan (ektrem-Radikal) maupun ekstrim kiri (liberal). Pemikrian keislaman mereka cukup moderat. Pemikrian keislaman yang moderat tersebut tidak lepas dari latar belakang dan lingkungan mereka yang berbasis di pesantren dan Nahdlatul Ulama' (NU). Sekalipun pemahaman terhadap Islam wasatiyah masih cukup dangkal, namun pasca PKM dari hasil testemini peserta sudah mangalami peningkatan yang signifikan.

c. PKM yang dilakukan secara partisipatoris dengan pendekatan Focus Discussion Group (FGD) berjalan cukup efektif, terarah dan sistematis. Hal ini dapat dilihat antara sebelum dan sesudah dilakukan PKM. Sejumlah peserta mengalami perkembangan wawasan keislaman yang signifikan. Signifikansi pemikiran tanpak dari pemaparan peserta yang dilakukan secara lisan maupun tulisan. Mereka mampu mengelaborasi pokok-pokok pikiran Islam wasatiyah secara sistematis dan relaitf utuh.

16 https://www.nu.or.id/post/read/92288/esensi-dakwah-islam-wasathiyah, diaskes pada tanggal 22 Februari 2021. 


\section{Daftar Pustaka}

Abd. Ghofur, "Telaah Kritis Masuk dan Berkembangnya Islam di Nusantara", Jurnal Ushuluddin, Vol. XVII No. 2, Juli 2011.

Abdullah bin Nuh, 1993. Kamus Baru, Jakarta: Pustaka Islam.

Abdurrahman Mas'ud, 2006. Dari Haramain ke Nusantara; Jejak Intelektual Arsitek Pesantren, Jakarta: Kencana.

Adrian Husaini, "Syari'at Islam di Indonesia; Problem Masyarakat Muslim Kontemporer", Tashwirul Afkar, Jurnal Refleksi Pemikiran Keagamaan dan Kebudayaan, Edisi No. 12 Tahun 2002.

Ahmad Syafi'i Mufid, "Peta Gerakan Radikalisme di Indonesia", makalah dipresentasikan dalam Workshop Membangun Kesadaran dan Strategi Menghadapi Radikaisasi Agama, Palu, 22 Mei 2012.

Handayani, Suci. 2006. Perlibatan Masyarakat Marginal Dalam Perencanaan dan Penganggaran Partisipasi (Cetakan Pertama). Surakarta: Kompip Solo

Khaled Abou El Fadl, Selamatkan Islam dari Muslim Puritan, terj. Helmi Mustafa (Jakarta: Serambi, 2007.

Laporan Sri Lestari, "Anak-anak Muda Indonesia Makin Radikal?, dalam http://www.bbc.com/indonesia/berita_indonesia, Januari 2016.

M. Dawam Raharjo, 1996. Ensiklopedi Al-Qur'an: Tafsir Sosial Berdasarkan Konsep-konsep Kunci, Jakarta: Yayasan Wakaf Paramadina.

M. Quraish Shihab, 2010. Membumikan Al-Qur'an, Jakarta: Lentera Hati.

M. Wasim Bilal, "Sinkretisme dalam Kontak Agama dan Budaya di Jawa", dalam Al-Jami'ah, No. 55/ 1994.

Marsel A. Boisard, Humanisme dalam Islam, 1980. terj. M. Rasyidi (Jakarta: Bulan Bintang.

Miftahuddin, "Islam Moderat Konteks Indonesia dalam Perspektif Historis", Mozaik, Vol. V, No. 1, Januari 2010.

Mohammed Arkoun, 1994. Nalar Islam dan Nalar Modern, Berbagai Tantangan dan Jalan Baru, Jakarta: INIS.

Motif Bom di Kawasan Sarinah Balas Dendam", Sindo, 14 Januari 2016.

Muhammad 'Ali Ash-Shabuni, Rawai' al-Bayan Tafsir Ayat al-Ahkam (Beirut: Dar-al-Fikr, tt.

Mutawalli Sha'rawi, 1991. Tafsir Sha'rawi, Mesir: Akhbar al-Yaum. 
Nasaruddin Umar, 1999. Argumen Kesetaraan GenderPerspektif al-Qur'an (Jakarta: Paramadina.

Norsaleha Mohd Salleh, et.al., "Wasatiyyah Discourse by the Perspective of Indonesian Muslim Scholars", Mediteranian Journal of Social Sciences, Vo. 6 No. 551, September 2015.

Rina Rehayati, "Minoritas Muslim, Belajar dari Kasus Minoritas Muslim fi Filipina", Jurnal Ushuluddin, Vol. XVII No. 2, Juli 2011.

Rusli, "Gagasan Khaled Abu Fadl tentang Islam Moderat versus Islam Puritan; Perspektif Sosiologi Pengetahuan", Jurnal Ilmu Ushuluddin, Vol. 8, No. 1, Januari 2009.

Syaikh Muhammad bin Shalih al-Usaimin, "Ma'na al-Wasith fi ad-Din", terj. Muhammad Iqbal Ahmad Ghazali, dalam islamlib.com, 2010.

Toshihiko Izutsu, 1997. Relasi Tuhan dan Manusia, terj. Agus Fahri Husein dkk. Yogyakarta: Tiara Wacana Yogya.

Ummi Sumbulah, , 2016. "Islam dan Risalah Profetik: Best practice Moderasi dan Kerahmatan", M. Zainuddin dan Muhammad In'am Esha (editor), Islam Moderat; Konsepsi, Interpretasi dan Aksi, Malang: UIN Maliki Press.

Usman Thalib, 2011. Sejarah Masuknya Islam di Maluku, Balai Pelestarian Sejarah dan Nilai Tradisional Provinsi Maluku dan Maluku Utara.

W. Mongomery Watt, 1972. Muhammad at Madina, New York: Oxford University Press.

W. Mongomery Watt, 1997. Fundamentalisme Islam dan Modernitas, Yogyakarta: Pustaka Pelajar.

Sbandi, Rukminto Adi. 2007. Perencanaan Partisipatoris Berbasis Aset Komunitas : Dari Pemikiran Menuju Penerapan. Depok: Fisip UI press

Slamet, M. 2003. Membentuk Pola Perilaku Manusia Pembangunan. Bogor: IPB Press

Yusuf Qardhawi, 1996. Islam Peradaban Masa Depan, terj. Musthalah Maufur (Jakarta: Pustaka al-Kausar.

Zayad Abd. Rahman, "Konsep Ummah dalam Al-Qur'an, Sebuah Upaya Melerai Miskonsepsi Negara Bangsa", dalam Religi: Jurnal Studi Islam, Vol. 6 Nomor 1, April 2015. 